\title{
Synergistic effect of nanosecond pulsed electric field combined with low-dose of pingyangmycin on salivary adenoid cystic carcinoma
}

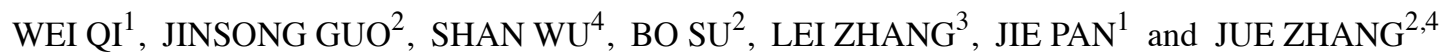 \\ ${ }^{1}$ Department of General Dentistry, Peking University School and Hospital of Stomatology, Beijing 100081; \\ ${ }^{2}$ Academy for Advanced Interdisciplinary Studies, Peking University, Beijing 100871; \\ ${ }^{3}$ Department of Oral and Maxillofacial Surgery, Peking University School and Hospital of Stomatology, \\ Beijing 100081; ${ }^{4}$ College of Engineering, Peking University, Beijing 100871, P.R. China
}

Received December 9, 2013; Accepted January 29, 2014

DOI: 10.3892/or.2014.3063

\begin{abstract}
Adenoid cystic carcinoma (ACC) is one of the most common malignant neoplasms in salivary glands. To evaluate the therapeutic effects of nanosecond pulsed electric field (nsPEF) combined with pingyangmycin (PYM) on salivary gland adenoid cystic carcinoma (SACC), ACC high metastatic cell line (SACC-LM) and low metastatic cell line (SACC-83) were tested by CCK-8 assay, cell clonogenic assay, flow cytometry and Transwell assay. Extracellular matrix metalloproteinase inducer (EMMPRIN) expression was tested by western blotting to verify the synergistic mechanism of nsPEF and PYM. The results showed that nsPEF inhibited the cell proliferation of both cell lines, and the inhibitory effect was strongly associated with time and electrical field strength. Moreover, PYM combined with nsPEF may enhance the suppression effect significantly, even at a very low dose $(0.01 \mu \mathrm{g} / \mathrm{ml})$. The synergistic effects may contribute to the downregulation of EMMPRIN expression resulting from the application of nsPEF. For SACC, nsPEF combined with chemotherapy agents may be a valuable strategy not only to improve the treatment effect and prognosis, but also to reduce the side-effects of chemotherapy.
\end{abstract}

\section{Introduction}

Adenoid cystic carcinoma (ACC) is one of the most common malignant neoplasms in salivary glands, which accounts for nearly $18 \%$ of all salivary gland malignancies (1). Generally, ACC has the following clinical and pathological characteristics: (i) progressive local growth, contributing to the

Correspondence to: Dr Jie Pan, Department of General Dentistry, Peking University School and Hospital of Stomatology, 22 Zhongguancun Nandajie, Haidian, Beijing 100081, P.R. China E-mail: panjie72@sina.com

Key words: salivary adenoid cystic carcinoma, nanosecond pulsed electric field, pingyangmycin, extracellular matrix metalloproteinase inducer, synergism difficulties in radical local resection and a high rate of local recurrence; (ii) aggressive histological features. For example, perineural invasion can lead to facial paralysis and difficulties in swallowing and pronunciation; (iii) a high incidence of distant metastasis, especially pulmonary originating from vascular involvement, which is the primary cause of patient mortality (2).

Conventionally, the treatment strategies for salivary adenoid cystic carcinoma (SACC) include local resection combined with postoperative radiation therapy, as the response rates of SACC to chemotherapy or molecular therapies are generally poor (3). In general, chemotherapy is delivered in cases of relapsed and/or metastatic disease almost exclusively with a palliative aim. Although many chemotherapy regimens have been attempted, to date, no randomized studies have been conducted to identify the best therapeutic option in this setting. Thus, combined treatments with several chemotherapy regimens, even chemopreventive agents, are often used (3). Nonetheless, due to the cytotoxicity and resistance of the chemotherapeutic drugs, patients always suffer from the drug side-effects; significant improvement is expected in local control or in overall survival.

Recently, clinicians realized that as an important transmembrane protein belonging to the immunoglobulin super family, extracellular matrix metalloproteinase inducer (EMMPRIN) plays a vital role in tumor proliferation, invasiveness and patient prognosis (4-6). Silencing of EMMPRIN expression can both restrain the proliferation, invasion and MMP-2/MMP-9 secretion in SACC cell lines in vitro, and suppress the tumor growth and perineural invasion in nude mice (7). Recent immunohistochemical studies showed that EMMPRIN expression was a significant prognosis factor and correlated with tumor size, perineural invasion, distant metastasis and clinical stage in patients with SACC. In addition, patients with positive-EMMPRIN expression had much poorer prognosis than those with negative-EMMPRIN expression (6).

As a promising physical therapy approach, nanosecond pulsed electric field (nsPEF) exhibits many notable nonthermal features, of which the duration of the electric pulses were maintained in nanoseconds level. Although not widely 
accepted, a few reports suggested that nsPEF may compromise the plasma membrane barrier function by disruption of the membrane potential $(8,9)$, followed by multiple physiological consequences including intracellular calcium bursts $(10,11)$, translocation of phosphatidylserine residues in plasma membrane $(12,13)$ and apoptotic cell death $(10,14)$. In vitro studies have confirmed that nsPEF inhibits cell proliferation in several human malignancies including melanoma, colon carcinoma, pancreatic cancer and squamous cell carcinoma (15-18). Furthermore, nsPEF could create synergistic effects in squamous cell carcinoma when combined with low-dose of gemcitabine (19). nsPEF was also found to suppress tumor growth in xenograft nude mice models of melanoma and squamous cell carcinoma $(15,20)$. However, the mechanisms underlying the suppression of cancer growth by nsPEF are complicated, and the effect of nsPEF on EMMPRIN expression has not previously been discussed.

In the present study, we demonstrated the synergistic inhibition effect of nsPEF combined with low-dose of PYM, which is a conventional chemotherapeutic agent widely used in China, in proliferation, apoptosis and invasion of two human SACC cell lines (SACC-83 and SACC-LM). Furthermore, EMMPRIN expression was investigated to clarify the synergistic effect of the nsPEF combined with PYM.

\section{Materials and methods}

Cell culture. Human low and high metastasis cell line of ACC (SACC-83 and SACC-LM), provided by the central laboratory of Peking University School and Hospital of Stomatology, were cultured in RPMI-1640 (Gibco, Grand Island, NY, USA) supplemented with $10 \%$ fetal bovine serum (FBS; HyClone, Logan, UT, USA), $100 \mathrm{U} / \mathrm{ml}$ penicillin and $100 \mathrm{U} / \mathrm{ml}$ streptomycin at $37^{\circ} \mathrm{C}$ in a humidified atmosphere of $5 \% \mathrm{CO}_{2}$.

Application of $n s P E F$. In the present study, an nsPEF generator was used with a duration of $100 \mathrm{~ns}$, and the electric fields may be adjusted from 10 to $30 \mathrm{kV} / \mathrm{cm}$. A digital phosphor oscilloscope (DPO4054; Tektronix, USA) equipped with a high voltage probe (P6015A; Tektronix) was applied to monitor the waveforms. The pulse power device is shown in Fig. 1. The SACC-83 and SACC-LM cells were harvested and resuspended in cell culture media with a concentration of $2.0 \times 10^{6}$ cells $/ \mathrm{ml}$. Cell suspension $\left(1 \times 10^{6}\right.$ cells) with $500 \mu \mathrm{l}$ was placed in $0.2 \mathrm{~cm}$ gap cuvette (Fig. 1B) (Biosmith, aluminum plate electrodes) and exposed to nsPEF. PYM with appropriate concentrations ranging from 0.01 to $100 \mu \mathrm{g} / \mathrm{ml}$ was applied to test the chemosensitivity of PYM to the SACC cells. To explore possible synergistic effects of nsPEF combined with low concentrations of PYM on SACC-83 and SACC-LM cells in vitro, $\mathrm{PYM}$ at a concentration of $0.01 \mu \mathrm{g} / \mathrm{ml}$ was applied alone or in combination after exposure to PYM. According to the different treatment, cells were divided into four groups. Group A was the control group in which neither nsPEF nor PYM was used. Group B was treated only by PYM. Group C was exposed to 40 pulses nsPEF with a field strength of 10,20 and $30 \mathrm{kV} / \mathrm{cm}$. Group D was treated with the combination of nsPEF and PYM. To explore the synergistic effect of nsPEF and PYM, the concentration of PYM in group D was as low as $0.01 \mu \mathrm{g} / \mathrm{ml}$ (Table I).

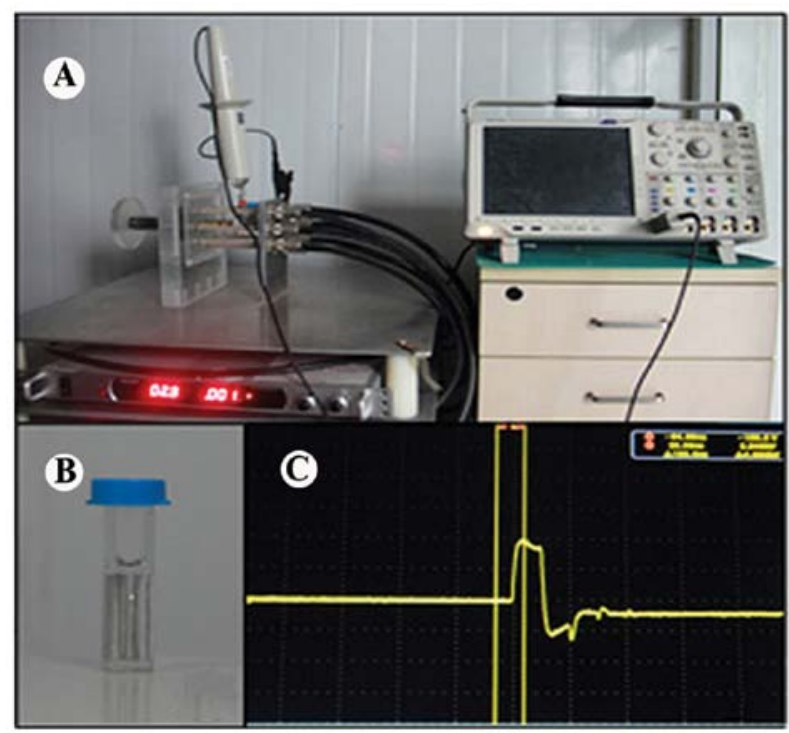

Figure 1. The experimental setup for nsPEF on SACC cells. nsPEF, nanosecond pulsed electric field; SACC, salivary adenoid cystic carcinoma.

Reagents and antibodies. Sodium pentobarbital was purchased from Sigma (St. Louis, MO, USA). Antibodies to EMMPRIN and $\beta$-actin were purchased from Bioworld Technology, USA. The secondary antibodies for western blotting were purchased from Santa Cruz Biotechnology, Inc. (Santa Cruz, CA, USA). PYM hydrochloride was purchased from Hebei Pharmaceutical Factory (Tianjin, China). Other chemicals and reagents were of analytical grade.

Cell proliferation test. The antiproliferative effect of PYM on SACC-83 and SACC-LM cells was determined with the Cell Counting Kit-8 (CCK-8). In the present study, we seeded $3 \times 10^{3}$ cells/well into 96 -well flat bottom plates (Costar, Cambridge, MA, USA), treated with PYM of the desired concentrations $(0.01,0.1,1.0,10,100 \mu \mathrm{g} / \mathrm{ml})$ when cells began to grow exponentially. After incubation for 24 and $48 \mathrm{~h}, 10 \mu \mathrm{l}$, WST-8 was added to each well, and the cells were further incubated at $37^{\circ} \mathrm{C}$ for $2 \mathrm{~h}$. Dye intensity was then read on a microplate reader (Bio-Rad, Hercules, CA, USA) at $450 \mathrm{~nm}$. The inhibition rate was calculated according to the formula: Inhibition rate $(\%)=($ absorbency of control - absorbency of treated cells)/absorbency of control x 100.

The inhibitory effect of PYM combined with nsPEF was investigated in the same way. SACC-83 and SACC-LM cells were harvested and resuspended with a concentration of $2.0 \times 10^{6}$ cells $/ \mathrm{ml}$. Cell suspension $\left(1 \times 10^{6}\right.$ cells) with $500 \mu 1$ was placed in $0.2 \mathrm{~cm}$ gap cuvette (Biosmith) and exposed to nsPEF. Cells in group D were then incubated with $0.01 \mu \mathrm{g} / \mathrm{ml}$ PYM after exposure to nsPEF. Then, we studied cell proliferation for 24 and 48 h by CCK- 8 assay.

Cell clonogenic assay. After exposure to different intensities of nsPEF of $0,10,20$ and $30 \mathrm{kV} / \mathrm{cm}$, SACC-83 and SACC-LM cells in control and treatment groups were seeded into 6-well plates in triplicates in $2 \mathrm{ml}$ medium containing $10 \% \mathrm{FBS}$ at $37^{\circ} \mathrm{C}$ for $6 \mathrm{~h}$ to allow attachment to the plastic bottom. The density of cells in group A, B, C and D with a field strength 
Table I. Basic parameters for treatment of SACC- 83 and SACC-LM cell lines.

\begin{tabular}{lcccc}
\hline Group & $\begin{array}{c}\mathrm{PYM} \\
\mu \mathrm{g} / \mathrm{ml}\end{array}$ & $\begin{array}{c}\text { Field strength } \\
\mathrm{kV} / \mathrm{cm}\end{array}$ & $\begin{array}{c}\text { Durations } \\
\text { Ns }\end{array}$ & Pulse no. \\
\hline A & 0 & - & - & - \\
B & 0.01 & - & - & - \\
C & 0 & $10,20,30$ & 100 & 40 \\
D & 0.01 & $10,20,30$ & 100 & 40 \\
\hline
\end{tabular}

A, control group; B, PYM group; C, nsPEF group; D, PYM plus nsPEF group. SACC, salivary adenoid cystic carcinoma; PYM, pingyangmycin; nsPEF, nanosecond pulsed electric field.

of $10 \mathrm{kV} / \mathrm{cm}$ was 1,000 cells/well, others were 3,000 cells/ well. The medium was then replaced by fresh culture medium with $0.01 \mu \mathrm{g} / \mathrm{ml}$ PYM concentration and cells were allowed to grow for another 7 days. The cell clones were fixed and stained with $0.1 \%$ crystal violet. Colonies $\geq 30$ cells were counted for computing growth inhibition rate.

Cell apoptosis analysis by flow cytometry. Apoptotic and necrotic cell death were analyzed by double staining with FITC-conjugated Annexin V and PI, which was based on the binding of Annexin $\mathrm{V}$ to apoptotic cells with exposed phosphatidylserine and PI labeling of late apoptotic/necrotic cells with membrane damage. In the present study, cells were suspended at $2 \times 10^{6}$ cells $/ \mathrm{ml}$ in RPMI-1640 containing $10 \%$ FBS and cells in group band group D $(10$ and $30 \mathrm{kV} / \mathrm{cm})$ were incubated with $0.01 \mu \mathrm{g} / \mathrm{ml}$ PYM after resuspension. After exposure to nsPEF, cells were incubated at $37^{\circ} \mathrm{C}$ for $2 \mathrm{~h}$. All the cells were collected and stained with FITC-conjugated Annexin $\mathrm{V}$ in a dark room for $3 \mathrm{~min}$, and then stained with PI on ice for $10 \mathrm{~min}$. Analysis of samples was carried out by FACSCanto flow cytometer (Becton-Dickinson, USA).

Cell invasion assay. Cell invasion was assessed by Boyden modified assay using Transwell chambers (Costar) with 8- $\mu \mathrm{m}$ pore polycarbonate filters that were coated with $50 \mu \mathrm{g} / \mathrm{ml}$ of Matrigel $^{\mathrm{TM}}$ (BD Biosciences, Bedford, MA, USA) diluted in serum-free medium. SACC-LM and SACC- 83 cells in group C and D were treated with nsPEF $(10 \mathrm{k}, 20$ and $30 \mathrm{kV} / \mathrm{cm})$ alone or plus PYM, respectively. Then, cells were seeded into the upper chambers with serum-free medium $\left(1.0 \times 10^{5}\right.$ cells/chamber $)$. Upper chambers were deposited in 24-well plates filled with RPMI-1640 10\% FBS and incubated for $24 \mathrm{~h}$ at $37^{\circ} \mathrm{C}$ in 5\% $\mathrm{CO}_{2}$. Non-migrating cells were removed from the upper surface of the chamber by scrubbing with a cotton swab. Migrated cells on the lower membrane were fixed in $100 \%$ methanol and stained with $0.1 \%$ crystal violet (Invitrogen) for $20 \mathrm{~min}$. Invasion cells were counted under the microscope.

Western blot analysis. In a preliminary western blot assay, we detected the expression of EMMPRIN of two cell lines $2 \mathrm{~h}$ after exposure to nsPEF $(30 \mathrm{kV} / \mathrm{cm})$. The difference in expression of EMMPRIN to the control group was notably detected $2 \mathrm{~h}$ following treatment. Therefore, after exposure to nsPEF, the two cell lines in each group were incubated at $37^{\circ} \mathrm{C}$ for $2 \mathrm{~h}$. Then, cells were collected and lysed in RIPA buffer $[150 \mathrm{mM}$ $\mathrm{NaCl}, 10 \mathrm{mM}$ Tris-HCl, $\mathrm{pH}$ 8.0, $1 \%$ Nonidet P-40 (NP-40), $0.5 \%$ deoxycholic acid, $0.1 \%$ SDS, $5 \mathrm{mM}$ EDTA] containing $0.7 \%$ phenylmethylsulfonyl fluoride (PMSF), $0.2 \%$ aprotinin, $0.2 \%$ leupeptin, and sodium metavanadate. Samples (30 $\mu \mathrm{g}$ protein) were separated on $12 \%(\mathrm{w} / \mathrm{v})$ SDS-PAGE gels, and electrophoretically transferred to PVDF membranes (Bio$\mathrm{Rad})$. Non-specific sites were blocked with solution containing 5\% non-fat milk powder in PBS/Tween-20 (PBS/T) for $1 \mathrm{~h}$ at room temperature. The membrane was probed with antibodies against $\beta$-actin and EMMPRIN in PBS/T containing $5 \%$ bovine serum albumin (BSA) overnight at $4{ }^{\circ} \mathrm{C}$, and then incubated with goat anti-rabbit secondary antibody at a dilution of 1:3,000.

Statistical analysis. Every group of experiments was carried out three times repeatedly and experimental data are expressed as mean values \pm standard deviation. The difference between each group was tested for significance using one-way ANOVA, post hoc, Bonferroni and Dunnett's test for analyses of multiple group comparisons. The synergism quotient (SQ) was evaluated by removing baseline values from all treatments and then dividing the effects of combined treatments by the sum of individual treatments. Synergism quotient $>1.0$ indicates that a synergism exists for a given measured response.

\section{Results}

nsPEF with PYM enhances the suppression effect of proliferation in the two cell lines. The inhibitory effect of PYM on proliferation of SACC-83 and SACC-LM was determined by CCK-8 assay. As shown in Figs. 2A and 3A, PYM significantly inhibited proliferation in both cell lines and the suppression effect is time- and dose-related. Based on these results, we set $0.01 \mu \mathrm{g} / \mathrm{ml}$ as the extremely low concentration for the combination treatment, which is much lower than the $\mathrm{IC}_{50}$ of PYM to SACC cells. Fig. 2B and C and Fig. 3B and C demonstrate the effects of nsPEF (10, 20 and $30 \mathrm{kV} / \mathrm{cm})$ and PYM alone and in combination in a CCK- 8 cell death assay 24 and $48 \mathrm{~h}$ following treatment. When used alone, there was a time- and electric field-dependent increase in nsPEF-induced cell death. The combination group shows an obviously synergistic effect of inhibition with the lower field strength 24 and $48 \mathrm{~h}$ after exposure, and the $\mathrm{IC}_{50}$ in group $\mathrm{D}$ is much lower than that of PYM. However, as the field strength of nsPEF increased, no marked synergistic but an enhancement effect was detected.

nsPEF with PYM enhances the inhibition effect of colony formation. As shown in Fig. 4, the results from the clonogenic assay are consistent with those of CCK-8 assay. Again, there is a field strength-dependent increase in inhibition of colony formation with either nsPEF treatment alone or in combination with PYM. Furthermore, nsPEF combined with low concentrations of PYM significantly inhibited cell growth in both cell lines.

nSPEF with PYM induces apoptosis and necrosis of both cell lines. The numbers of apoptotic and necrotic cells were determined by Annexin V-FITC and PI double staining. With 

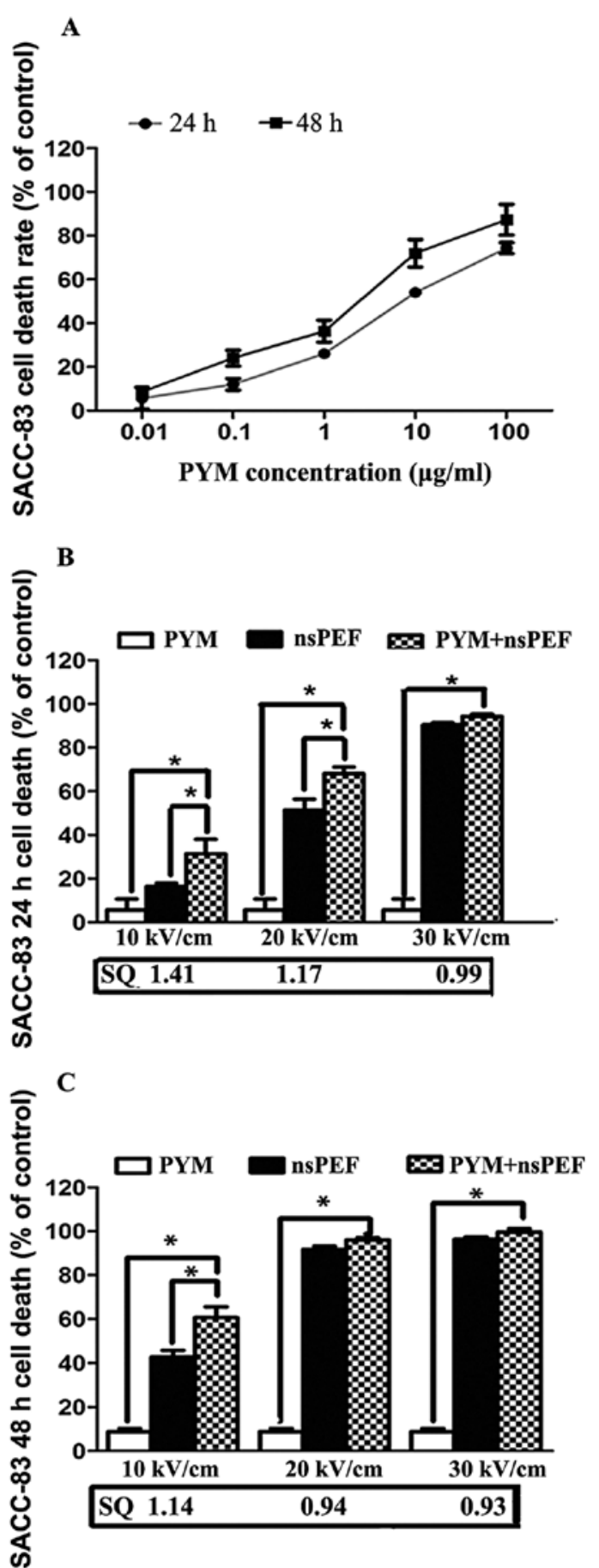

Figure 2. Effects of nsPEF combined with PYM on growth inhibition in SACC- 83 cells. Inhibition of cell proliferation was assessed by MTT assay. (A) SACC-83 cells were treated with various concentrations of PYM for 24 and $48 \mathrm{~h}$. (B and C) Cell death rates of SACC- 83 cells were determined following combination treatment for 24 and $48 \mathrm{~h}$, respectively. Results are presented as the percentage of the decreased values from the control cells. Data are from three independent experiments, each in triplicate, and are expressed as mean values \pm standard deviation $(" \mathrm{p}<0.05)$. nsPEF, nanosecond pulsed electric field; PYM, pingyangmycin; SACC, salivary adenoid cystic carcinoma.

a lower electric field, nsPEF played a mild role in inducing cell apoptosis in the two cell lines. When the voltage was increased to $30 \mathrm{kV} / \mathrm{cm}$, a great number of SACC- 83 cells underwent necrosis whereas numerous SACC-LM cells underwent
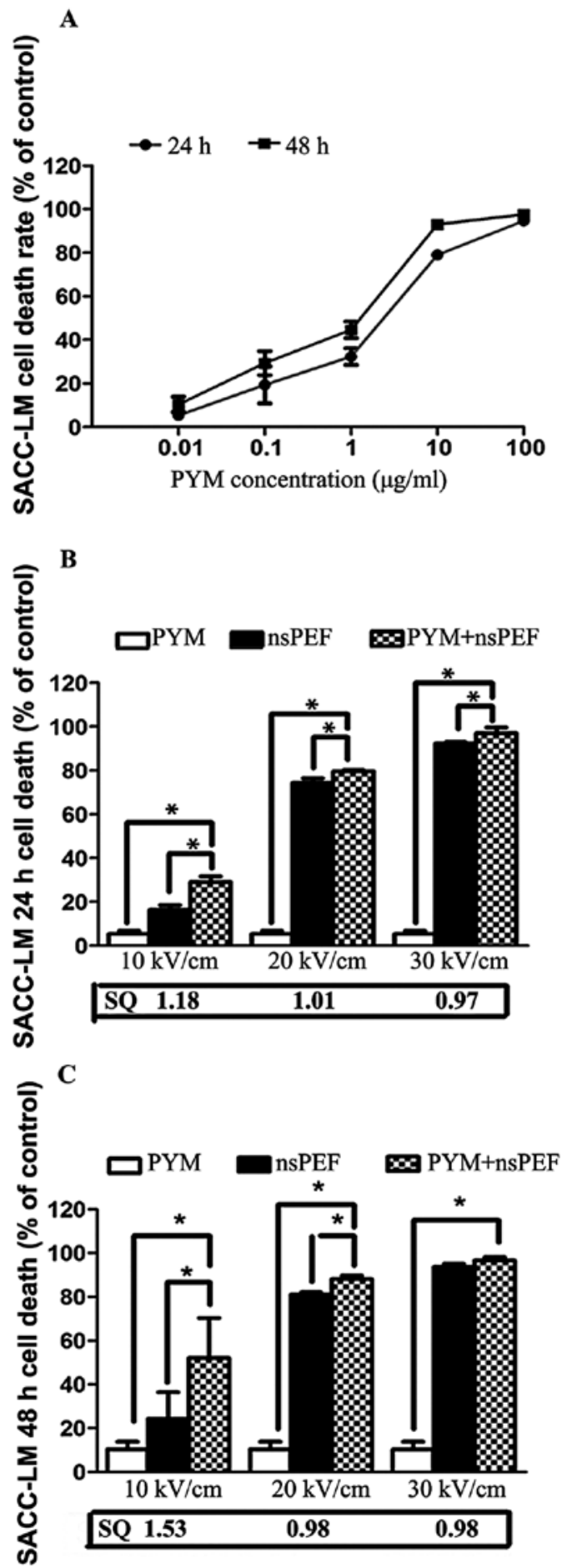

Figure 3. Effects of nsPEF combined with PYM on growth inhibition in SACC-LM cells. Inhibition of cell proliferation was assessed by MTT assay. (A) SACC-LM cells were treated with various concentrations of PYM for 24 and 48 h. (B and C) Cell death rates of SACC-LM cells were determined following combination treatment for 24 and $48 \mathrm{~h}$. Results are presented as the percentage of the decreased values from the control cells. Data are from three independent experiments, each in triplicate, and are expressed as mean values \pm standard deviation $(\mathrm{p}<0.05)$. nsPEF, nanosecond pulsed electric field; PYM, pingyangmycin; SACC, salivary adenoid cystic carcinoma.

apoptosis (Fig. 5). When combined with PYM, a synergistic effect on apoptosis and necrosis was detected in both cell lines although no significant effect on promoting apoptosis or necrosis was detected when PYM was used alone. 

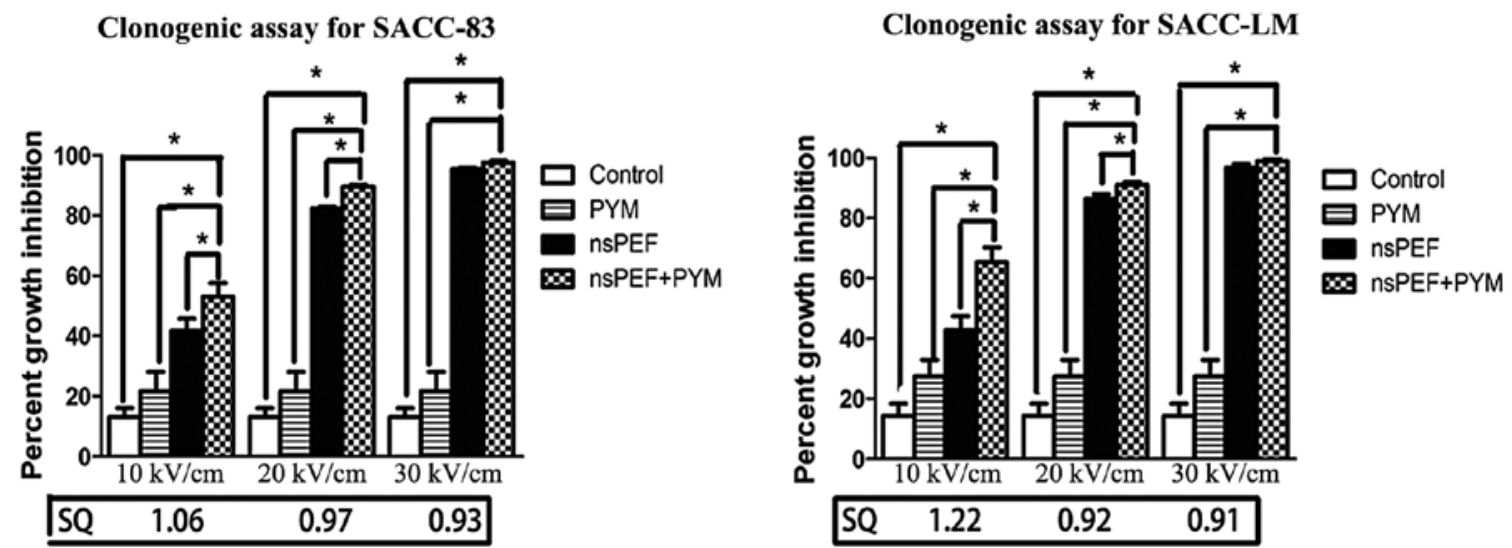

Figure 4. Effect of the combination of nsPEF and PYM in the colony formation of SACC-LM and SACC-83 cells. Data are expressed as the percentage of growth inhibition in reference to the growth of untreated control cells ( $\left.{ }^{*} \mathrm{p}<0.05\right)$. nsPEF, nanosecond pulsed electric field; PYM, pingyangmycin; SACC, salivary adenoid cystic carcinoma.

A Flow cytometry assay for SACC-83 cells

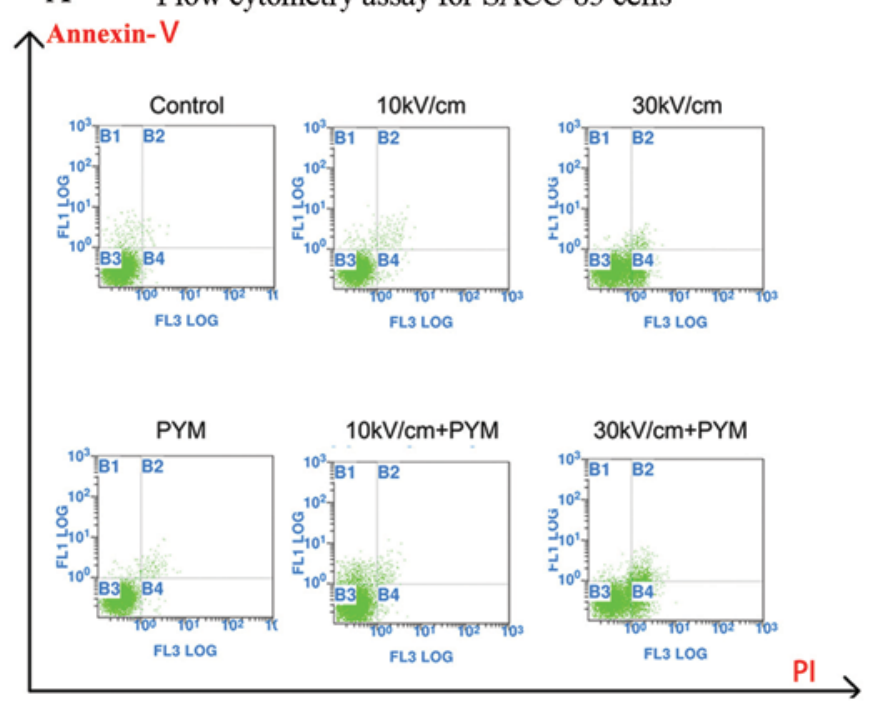

D Flow cytometry assay for SACC-LM cells

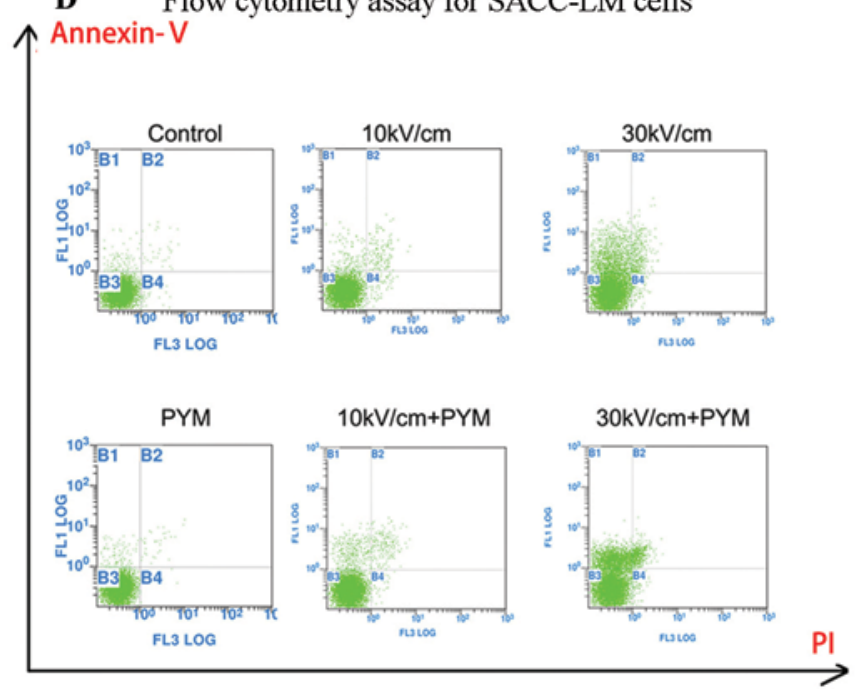

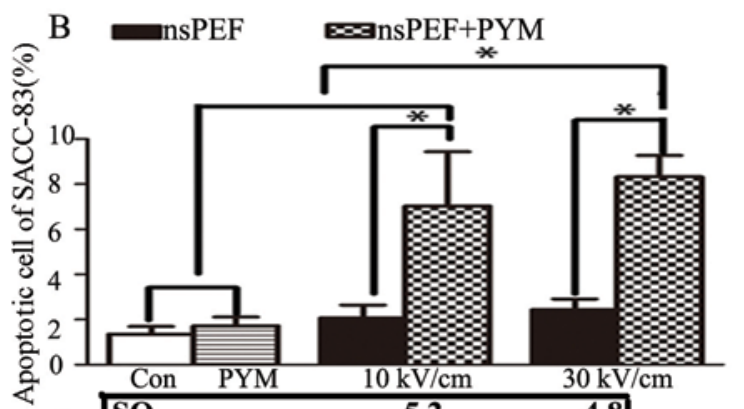
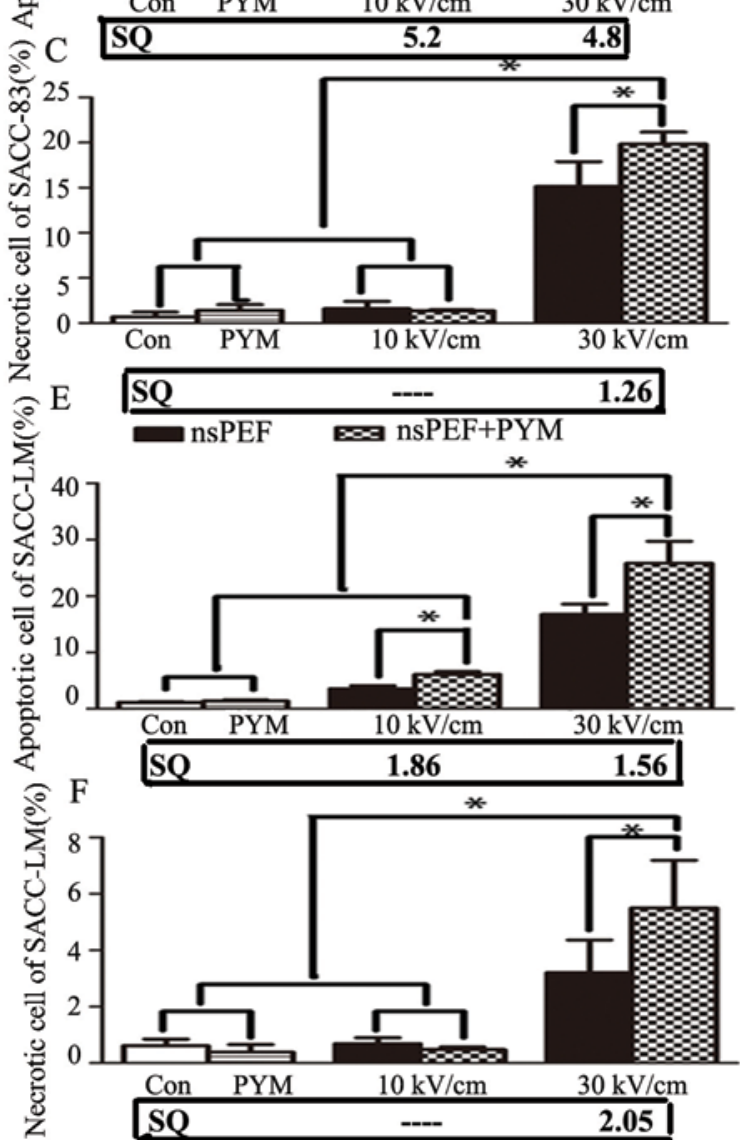

Figure 5. nsPEF combined with PYM significantly induces SACC-83 and SACC-LM cell necrosis and apoptosis. (A and D) The characterization of necrosis and apoptosis after PI and Annexin V-FITC staining. (B, C, E and F) A great number of SACC-LM cells underwent apoptosis when exposed to nsPEF with a field strength of $30 \mathrm{kV} / \mathrm{cm}$ whereas more SACC-83 cells underwent necrosis in the same conditions $\left({ }^{*} \mathrm{p}<0.05\right)$. Experimental data are expressed as mean values \pm standard deviation. nsPEF, nanosecond pulsed electric field; PYM, pingyangmycin; SACC, salivary adenoid cystic carcinoma. 
A

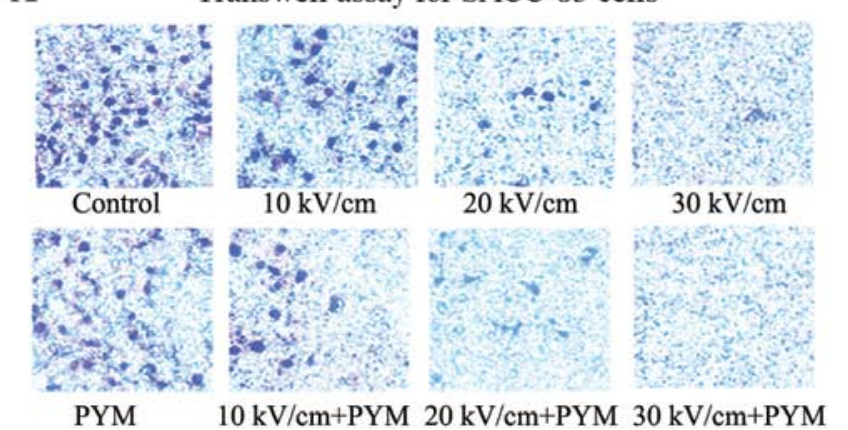

B

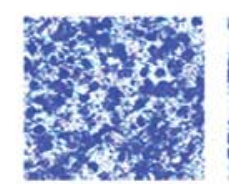

Control

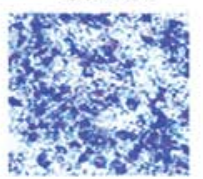

PYM
Transwell assay for SACC-LM cells

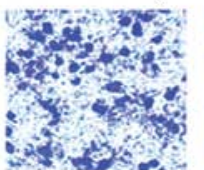

$10 \mathrm{kV} / \mathrm{cm}$

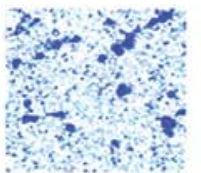

$20 \mathrm{kV} / \mathrm{cm}$

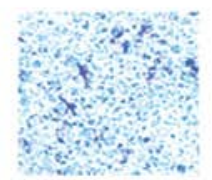

$30 \mathrm{kV} / \mathrm{cm}$
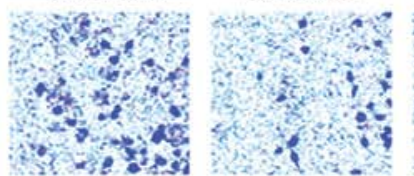

setorita

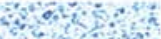

D $\square$ Con $\square$ PYM $\square$ nsPEF $\circledast$ nsPEF+PYM

$\mathrm{C} \square$ Con $\square \mathrm{PYM}$

nsPEF $ळ$ nsPEF+PYM

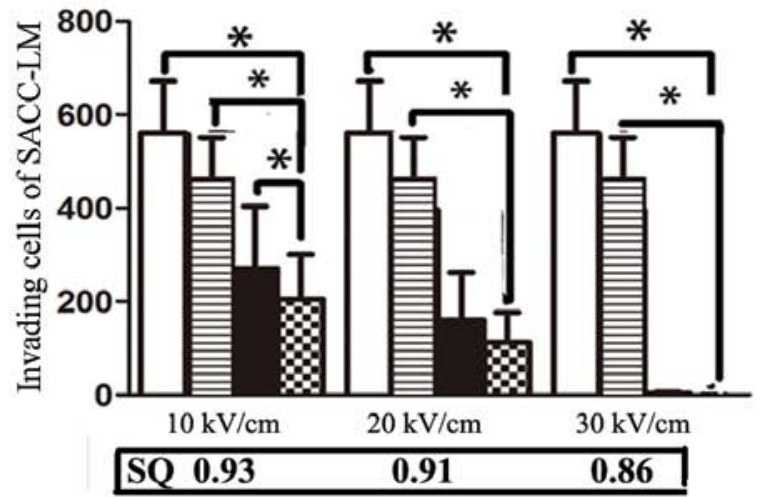

Figure 6. Invasion assay by nsPEF and PYM combination treatment. (A and B) The representative microscopic fields of invasion cells on the bottom of Transwell inserts. (C and D) Quantization of cell invasion assay by counting the invaded cells. Three microscopic fields were arbitrarily chosen and the average invaded cell number was determined $\left({ }^{*} \mathrm{p}<0.05\right)$. Experimental data are expressed as mean values \pm standard deviation. nsPEF, nanosecond pulsed electric field; PYM, pingyangmycin.

A EMMPRIN expression of SACC-83 cells

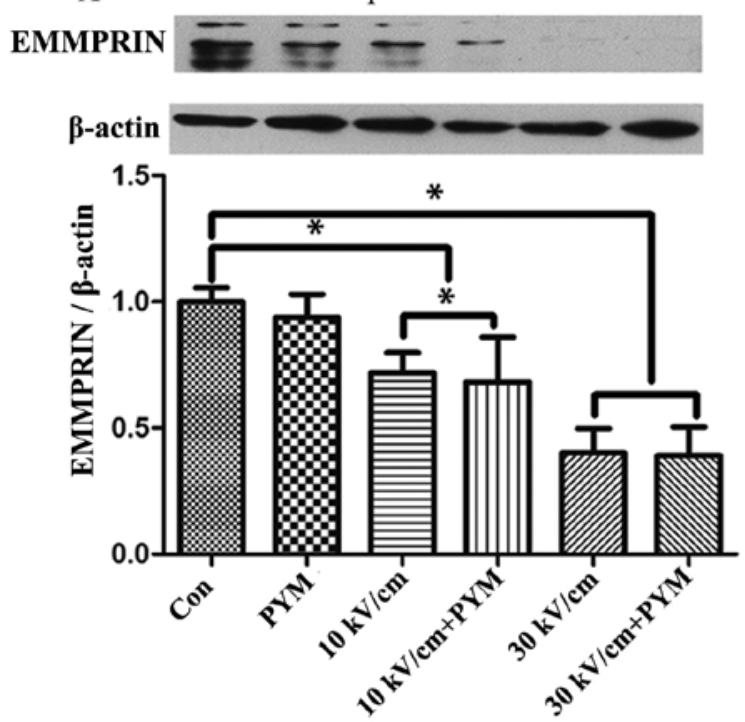

B EMMPRIN expression of SACC-LM cells

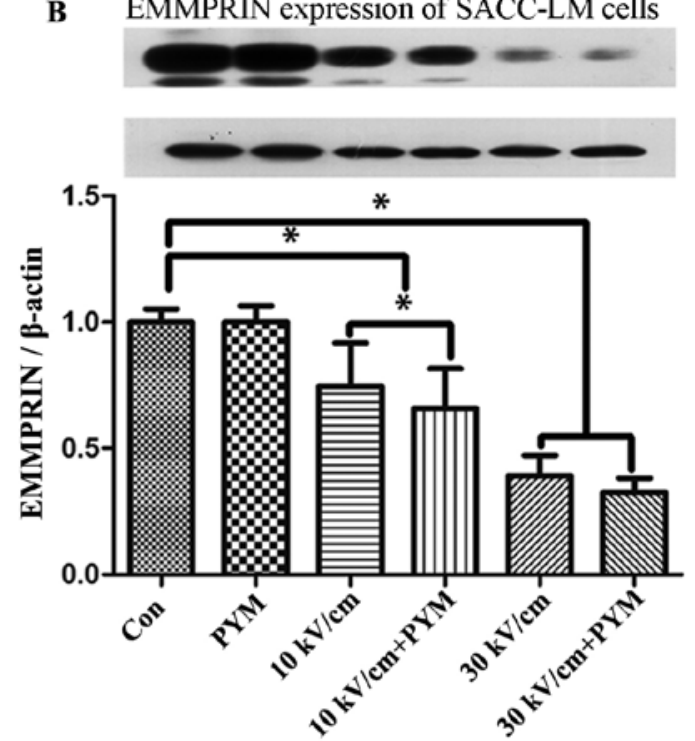

Figure 7. Difference in EMMPRIN expression $2 \mathrm{~h}$ after exposure to nsPEF and PYM ( $\mathrm{p}<0.05$ ). (A) EMMPRIN expression of SACC-83 cells. (B) EMMPRIN expression of SACC-LM cells. Experimental data are expressed as mean values \pm standard deviation.

nsPEF with PYM inhibits the invasion of SACC-83 and SACC-LM cells. As shown in Fig. 6, SACC-LM cells exhibited more aggressive behavior than SACC-83 cells, which is in consistent with the characteristics of the two cell lines. Both nsPEF and PYM inhibit the invasion potential of SACC cells. In addition, the inhibition of nsPEF alone or in combination with PYM for migration in both cell lines was electrical field strength-related, and when the field strength increased to $30 \mathrm{kV} / \mathrm{cm}$, the cells that transmit the polycarbonate filters were hardly detected. As is shown in Fig. 6, PYM statistically enhanced the effect of nsPEF although only a weak synergism was detected in SACC-83 cells with a lower electric field $(10 \mathrm{kV} / \mathrm{cm})$. 
nSPEF and PYM inhibit the expression of EMMPRIN in SACC-83 and SACC-LM cells. The difference in EMMPRIN expression of SACC-83 and SACC-LM was investigated $2 \mathrm{~h}$ after exposure to nsPEF, as shown in Fig. 7. The results suggested that EMMPRIN expression suppression of nsPEF on SACC-83 and SACC-LM cells is electric field-correlated. In addition, it was found that PYM does not affect EMMPRIN expression when used alone with a low concentration $(0.01 \mu \mathrm{g} / \mathrm{ml})$, even under the administration of nsPEF.

\section{Discussion}

Adenoid cystic carcinoma (ACC) is characterized by extensive local invasion and a tendency for distant metastasis (21-23). The mainstay of treatment is comprehensive therapy which includes local resection combined with postoperative radiation. However, both may lead to aesthetic or functional complications, especially for young people. The present study found that nsPEF combined with low-dose PYM may act synergistically and develop an effective inhibitory effect in the proliferation, apoptosis and invasion of SACC cells in vitro. As the side-effects of nsPEF and chemotherapy in a low dose are minimal, it provides a potential strategy for SACC treatment.

nsPEF has emerged as an anticancer strategy by inducing cell death in many tumors $(16,19,24,25)$. nsPEF may interact with plasma membranes and intracellular organelles, resulting in the DNA damage, cellular calcium bursts, apoptosis or other forms of cell death $(10,26)$. It has been confirmed that nsPEF may inhibit proliferation of several types of neoplasm in vitro and in vivo, and the death induced by nsPEF is depended on cell type (17). Our results showed that nsPEF induced apoptosis of the two cell lines in a relatively low field strength, whereas when the field strength increased to $30 \mathrm{kV} /$ $\mathrm{cm}$, the proportion of SACC-83 cells that underwent necrosis was more than that of apoptosis. Moreover, we observed that nsPEF inhibited proliferation of SACC-83 and SACC-LM cells significantly and the suppression was electric fielddependent. Although ignorable when applied with $10 \mathrm{kV} / \mathrm{cm}$ alone to SACC-LM cells, the inhibitory effect of the applied nsPEF may be improved significantly when combined with low-dose of PYM.

PYM has been applied in clinical chemotherapy in China since 1979 (27,28), and it has been fairly extensively used in chemotherapy for treatment of squamous cell carcinoma, malignant lymphoma, Hodgkin's disease, breast cancer and ACC (3,29-31). Principally, PYM exerts its chemotherapeutic effects through damage to cellular DNA (32). Tai et al found that the cytotoxic effect of PYM on KB cells was concentration-dependent (33). Morphological changes in KB cells treated with a lower dose of PYM showed features of necrosis $24 \mathrm{~h}$ after exposure, whereas the number of apoptotic cells increased significantly when the concentration was increased 100-fold. Tai et al proposed that the mechanism of cell death resulted from PYM depended on the number of PYM molecules present inside the cell and PYM may cross the cell by passive diffusion. However, PYM overdose often leads to several complications involving multiple organs and systems, especially pulmonary fibrosis (34-36). Thus, the comprehensive treatment was widely considered to minimize the side-effects and improve the therapeutic efficacy.
The synergism of nsPEF with very low doses of PYM found in our study demonstrates a possibility for further clinical use. First, the results showed that PYM inhibited proliferation of SACC cells in a dose- and time-dependent manner. Meanwhile, we found the significant synergistic activity with combination treatment of nsPEF and low dose of PYM to inhibit proliferation, induce apoptosis and necrosis in the two cell lines as detected by flow cytometry. However, not synergism but an enhancement effect was exhibited in the high field strength group in CCK-8 assay, clonogenic assay and Transwell assay, which contributed to the high efficiency of nsPEF. The PYM crosses the cell by passive diffusion and the nano-pores caused by nsPEF were small and short lived (37); thus, we speculated that the sites or pathways that nsPEF and PYM acted on were different, rather than enhancement of PYM passive diffusion.

EMMPRIN is widely expressed in various cancer cell lines and is associated with an invasive phenotype of various types of tumors, including SACC $(4,38,39)$. In the present study, we observed that the suppression effect of nSPEF on EMMPRIN expression was field strength-dependent. When combined with a low dose of PYM, EMMPRIN expression was not decreased significantly, which suggests that EMMPRIN was not a common target for the two treatments. Grass et al proved that EMMPRIN may induce breast epithelial cell invasiveness by promoting the EGFR-Ras-ERK signaling pathway (5). Furthermore, PYM could inhibit esophageal squamous cell carcinoma proliferation by downregulating EGFR expression (30). It has been proved that EGFR is highly expressed in ACC $(40,41)$ and is involved in cell proliferation, motility, adhesion, invasion, angiogenesis and survival $(42,43)$. In other words, PYM may not inhibit SACC cell proliferation and invasion through EMMPRIN directly, but may suppress EGFR expression to play a synergistic effect combined with nsPEF.

Multi-drug resistance (MDR) of tumor cells towards chemotherapeutic drugs is the main reason for failure of chemotherapy. EMMPRIN played a vital role in MDR (44), and mediated chemoresistance of various types of cancer in several pathways, such as increasing the expression of P-glycoprotein (MDR1/ABCB1), stimulating phosphoinositide 3-kinase/AKT cell survival signaling pathway (an anti-apoptosis pathway), and upregulating MMP expression $(45,46)$. However, the relationship between PYM resistance and the pathways referred above remain unknown. Zheng et al (47) found that carbonic anhydrase 9 (CA9) served as a contributor to PYM resistance in human tongue cancer and silencing CA9 may improve PYM chemosensitivity. Recent studies have shown that EMMPRIN is associated with CA9 expression and indicates an adverse prognosis in breast cancer (48). Hence, we proposed that nsPEF enhanced the chemosensitivity of SACC cell lines to PYM indirectly through suppression of EMMPRIN expression and led to the synergism.

It was of vital clinical significance that regardless the pathways or sites that PYM impacted, nsPEF was able to inhibit the EMMPRIN expression that played a central role in MDR. In other words, nsPEF may improve the chemosensitivity of other chemotherapeutic drugs which shared the mechanism of chemoresistance referred. Furthermore, as shown in the present study, nsPEF with appropriate electric field may also serve 
as an effective treatment for SACC. The proposed approach which combines nsPEF with PYM may be a promising way to inactivate SACC tumor cells, and it may also markedly reduce the side-effects due to the extremely low dose of chemotherapy used.

In conclusion, the present study demonstrated that there is a synergistic effect in SACC cell lines when nsPEF is combined with a low dose of PYM, a commonly used chemotherapy agent, and it may provide a valuable tool to treat SACC. Western blot results suggested that the mechanism for this synergism is probably due to the suppression of EMMPRIN expression induced by nsPEF. Further studies will be carried out in EMMPRIN-targeted cancer therapy induced by nsPEF.

\section{Acknowledgements}

The authors thank Shenglin Li, Xin Cong and Lingfei Jia for their excellent technical assistance.

\section{References}

1. Li LJ, Li Y, Wen YM, Liu H and Zhao HW: Clinical analysis of salivary gland tumor cases in West China in past 50 years. Oral Oncol 44: 187-192, 2008.

2. Rapidis AD, Givalos N, Gakiopoulou H, et al: Adenoid cystic carcinoma of the head and neck. Clinicopathological analysis of 23 patients and review of the literature. Oral Oncol 41: 328-335, 2005.

3. Dodd RL and Slevin NJ: Salivary gland adenoid cystic carcinoma: a review of chemotherapy and molecular therapies. Oral Oncol 42: 759-769, 2006.

4. Fink K and Boratyński J: The role of metalloproteinases in modification of extracellular matrix in invasive tumor growth, metastasis and angiogenesis. Postepy Hig Med Dosw (Online) 66: 609-628, 2012 (In Polish).

5. Grass GD, Tolliver LB, Bratoeva M and Toole BP: CD147, CD44, and the epidermal growth factor receptor (EGFR) signaling pathway cooperate to regulate breast epithelial cell invasiveness. J Biol Chem 288: 26089-26104, 2013.

6. Yang X, Dai J, Li T, et al: Expression of EMMPRIN in adenoid cystic carcinoma of salivary glands: correlation with tumor progression and patients' prognosis. Oral Oncol 46: 755-760, 2010.

7. Yang X, Zhang P, Ma Q, et al: EMMPRIN silencing inhibits proliferation and perineural invasion of human salivary adenoid cystic carcinoma cells in vitro and in vivo. Cancer Biol Ther 13: 85-91, 2012.

8. Kotnik T and Miklavcic D: Theoretical evaluation of voltage inducement on internal membranes of biological cells exposed to electric fields. Biophys J 90: 480-491, 2006.

9. Gowrishankar TR and Weaver JC: Electrical behavior and pore accumulation in a multicellular model for conventional and supra-electroporation. Biochem Biophys Res Commun 349: 643-653, 2006

10. Beebe SJ, Fox PM, Rec LJ, Willis EL and Schoenbach KH: Nanosecond, high-intensity pulsed electric fields induce apoptosis in human cells. FASEB J 17: 1493-1495, 2003.

11. Vernier PT, Sun Y, Marcu L, Salemi S, Craft CM and Gundersen MA: Calcium bursts induced by nanosecond electric pulses. Biochem Biophys Res Commun 310: 286-295, 2003.

12. Vernier PT, Sun Y, Marcu L, Craft CM and Gundersen MA: Nanoelectropulse-induced phosphatidylserine translocation. Biophys J 86: 4040-4048, 2004.

13. Vernier PT, Ziegler MJ, Sun Y, Gundersen MA and Tieleman DP: Nanopore-facilitated, voltage-driven phosphatidylserine translocation in lipid bilayers - in cells and in silico. Phys Biol 3: 233-247, 2006.

14. Beebe SJ, Blackmore PF, White J, Joshi RP and Schoenbach KH: Nanosecond pulsed electric fields modulate cell function through intracellular signal transduction mechanisms. Physiol Meas 25: 1077-1093, 2004.

15. Nuccitelli R, Pliquett U, Chen X, et al: Nanosecond pulsed electric fields cause melanomas to self-destruct. Biochem Biophys Res Commun 343: 351-360, 2006.
16. Hall EH, Schoenbach KH and Beebe SJ: Nanosecond pulsed electric fields induce apoptosis in p53-wildtype and p53-null HCT116 colon carcinoma cells. Apoptosis 12: 1721-1731, 2007.

17. Ren W and Beebe SJ: An apoptosis targeted stimulus with nanosecond pulsed electric fields (nsPEFs) in E4 squamous cell carcinoma. Apoptosis 16: 382-393, 2011.

18. Nuccitelli R, Lui K, Kreis M, Athos B and Nuccitelli P: Nanosecond pulsed electric field stimulation of reactive oxygen species in human pancreatic cancer cells is $\mathrm{Ca}^{2+}$-dependent. Biochem Biophys Res Commun 435: 580-585, 2013.

19. Wang J, Guo J, Wu S, et al: Synergistic effects of nanosecond pulsed electric fields combined with low concentration of gemcitabine on human oral squamous cell carcinoma in vitro. PLoS One 7: e43213, 2012.

20. Chen X, Kolb JF, Swanson RJ, Schoenbach KH and Beebe SJ: Apoptosis initiation and angiogenesis inhibition: melanoma targets for nanosecond pulsed electric fields. Pigment Cell Melanoma Res 23: 554-563, 2010.

21. Szanto PA, Luna MA, Tortoledo ME and White RA: Histologic grading of adenoid cystic carcinoma of the salivary glands. Cancer 54: 1062-1069, 1984.

22. van der Wal JE, Becking AG, Snow GB and van der Waal I: Distant metastases of adenoid cystic carcinoma of the salivary glands and the value of diagnostic examinations during follow-up. Head Neck 24: 779-783, 2002.

23. Gao M, Hao Y, Huang MX, et al: Clinicopathological study of distant metastases of salivary adenoid cystic carcinoma. Int $\mathbf{J}$ Oral Maxillofac Surg 42: 923-928, 2013.

24. Ren W, Sain NM and Beebe SJ: Nanosecond pulsed electric fields (nsPEFs) activate intrinsic caspase-dependent and caspaseindependent cell death in Jurkat cells. Biochem Biophys Res Commun 421: 808-812, 2012.

25. Nuccitelli R, Tran K, Sheikh S, Athos B, Kreis M and Nuccitelli P: Optimized nanosecond pulsed electric field therapy can cause murine malignant melanomas to self-destruct with a single treatment. Int J Cancer 127: 1727-1736, 2010.

26. Stacey M, Stickley J, Fox P, et al: Differential effects in cells exposed to ultra-short, high intensity electric fields: cell survival, DNA damage, and cell cycle analysis. Mutat Res 542: 65-75, 2003.

27. He NG, Zhang HQ, Wang RH, Yang XL and Xue SB: Enhancement of antitumor activity of bleomycin A5 in mouse sarcoma 180 cells in vitro and in vivo by verapamil. Zhongguo Yao Li Xue Bao 11: 381-384, 1990 (In Chinese).

28. He NG, Zhang HQ, Song PG, Liu ZM and Xue SB: Mechanism of enhancement of bleomycin A5 antitumor activity by verapamil. Yao Xue Xue Bao 26: 15-19, 1991 (In Chinese).

29. Yue H, Qian J, Elner VM, et al: Treatment of orbital vascular malformations with intralesional injection of pingyangmycin. Br J Ophthalmol 97: 739-745, 2013.

30. Gong JH, Liu XJ, Li Y and Zhen YS: Pingyangmycin downregulates the expression of EGFR and enhances the effects of cetuximab on esophageal cancer cells and the xenograft in athymic mice. Cancer Chemother Pharmacol 69: 1323-1332, 2012.

31. Gong L, Lou JY, Wang P, Zhang JW, Liu H and Peng ZL: Clinical evaluation of neoadjuvant chemotherapy followed by radical surgery in the management of stage IB2-IIB cervical cancer. Int J Gynaecol Obstet 117: 23-26, 2012.

32. Tai KW, Chang YC, Chou LS and Chou MY: Cytotoxic effect of pingyangmycin on cultured KB cells. Oral Oncol 34: 219-223, 1998.

33. Tai KW, Chou MY, Hu CC, Yang JJ and Chang YC: Induction of apoptosis in KB cells by pingyangmycin. Oral Oncol 36: 242-247, 2000.

34. Ji Y, Wang T, Wei ZF, et al: Paeoniflorin, the main active constituent of Paeonia lactiflora roots, attenuates bleomycin-induced pulmonary fibrosis in mice by suppressing the synthesis of type I collagen. J Ethnopharmacol 149: 825-832, 2013.

35. Trujillo G, Hartigan AJ and Hogaboam CM: T regulatory cells and attenuated bleomycin-induced fibrosis in lungs of CCR $7^{-1-}$ mice. Fibrogenesis Tissue Repair 3: 18, 2010.

36. Zhou C, Han W, Zhang P, Cai M, Wei D and Zhang C: Lycopene from tomatoes partially alleviates the bleomycin-induced experimental pulmonary fibrosis in rats. Nutr Res 28: 122-130, 2008.

37. Pakhomov AG, Shevin R, White JA, et al: Membrane permeabilization and cell damage by ultrashort electric field shocks. Arch Biochem Biophys 465: 109-118, 2007.

38. Huang ZQ, Chen WL, Li HG, Li JS, Xu ZY and Lin ZY: Extracellular matrix metalloproteinase inducer expression in salivary gland tumors: a correlation with microvessel density. J Craniofac Surg 21: 1855-1860, 2010. 
39. Kim H, Zhai G, Liu Z, et al: Extracelluar matrix metalloproteinase as a novel target for pancreatic cancer therapy. Anticancer Drugs 22: 864-874, 2011.

40. Hitre E, Budai B, Takácsi-Nagy Z, et al: Cetuximab and platinumbased chemoradio- or chemotherapy of patients with epidermal growth factor receptor expressing adenoid cystic carcinoma: a phase II trial. Br J Cancer 109: 1117-1122, 2013.

41. Huang $\mathrm{Y}, \mathrm{Yu} \mathrm{T}, \mathrm{Fu} \mathrm{X}$, et al: EGFR inhibition prevents in vitro tumor growth of salivary adenoid cystic carcinoma. BMC Cell Biol 14: 13, 2013.

42. Huang SM and Harari PM: Epidermal growth factor receptor inhibition in cancer therapy: biology, rationale and preliminary clinical results. Invest New Drugs 17: 259-269, 1999.

43. Woodburn JR: The epidermal growth factor receptor and its inhibition in cancer therapy. Pharmacol Ther 82: 241-250, 1999.

44. Chen H, Wang L, Beretov J, Hao J, Xiao W and Li Y: Co-expression of CD147/EMMPRIN with monocarboxylate transporters and multiple drug resistance proteins is associated with epithelial ovarian cancer progression. Clin Exp Metastasis 27: 557-569, 2010 .
45. Kuang $\mathrm{YH}$, Chen $\mathrm{X}, \mathrm{Su} \mathrm{J}$, et al: RNA interference targeting the CD147 induces apoptosis of multi-drug resistant cancer cells related to XIAP depletion. Cancer Lett 276: 189-195, 2009.

46. Yang JM, Xu Z, Wu H, Zhu H, Wu X and Hait WN: Overexpression of extracellular matrix metalloproteinase inducer in multidrug resistant cancer cells. Mol Cancer Res 1: 420-427, 2003.

47. Zheng G, Zhou M, Ou X, et al: Identification of carbonic anhydrase 9 as a contributor to pingyangmycin-induced drug resistance in human tongue cancer cells. FEBS J 277: 4506-4518, 2010.

48. Pinheiro C, Sousa B, Albergaria A, et al: GLUT1 and CAIX expression profiles in breast cancer correlate with adverse prognostic factors and MCT1 overexpression. Histol Histopathol 26 : 1279-1286, 2011. 